\title{
Effect of Team-based Learning on Second Year Students' Academic Performance
}

\author{
Memoona Mansoor1, Syed Moyn Aly² and Arshad Javaid3 \\ IDepartment of Medical Education, Islamabad Medical and Dental College, Islamabad, Pakistan \\ ${ }^{2}$ Department of Medical Education, Jinnah Sindh Medical University, Karachi, Pakistan \\ ${ }^{3}$ Department of Anatomy, Shifa College of Medicine, Islamabad, Pakistan
}

\begin{abstract}
Objective: To determine if there was any significant difference in scores of students who acquired knowledge through team-based learning (TBL) versus those who learned through small group discussion (SGD).

Study Design: Quasi-experimental cross-over study.

Place and Duration of Study: Shifa College of Medicine, Islamabad, from March to December 2015.

Methodology: All students of second year MBBS were assigned to either TBL or SGD, based on non-probability sampling, for 8 themes in a five-week module. The groups were flipped after 4 themes. TBL format recommended by the AMEE guide No: 65 was followed. The impact of both learning methods was assessed by comparing end-of-module written examination scores of the two groups through independent sample t-test. SPSS version 23 was used for data analysis. A p-value of $\leq 0.05$ was considered statistically significant.

Results: End-of-module written examination scores showed there was no significant difference in student academic performance when they studied with TBL or SGD in themes 1-4 (TBL $61.90 \pm 13.01$ versus SGD 59.65 $\pm 11.56, p=0.41$ ). However, for themes 5-8 there was a significant difference in scores (TBL $65.36 \pm 11.62$ versus SGD 59.92 $\pm 10.65, p=0.03$ ) A trend towards higher scores was observed in content learned with TBL in all eight themes.

Conclusion: TBL is equally effective as an instructional method as SGD. However, it could not be established that it results in significant improvement in learning.
\end{abstract}

Key Words: Team-based learning (TBL), Academic performance, Student scores.

How to cite this article: Mansoor M, Aly SM, Javaid A. Effect of team-based learning on second year students' academic performance. J Coll Physicians Surg Pak 2019; 29(9):860-4.

\section{INTRODUCTION}

Team-based learning (TBL) was devised as an instructional strategy for teaching business by Dr. Michaelsen. Its advent in medical education dates back to 2001, when it was introduced in the Baylor Medical College, Texas. ${ }^{1}$ Since then, it has been widely used as a dynamic, learner-centred instructional strategy not only in the medical schools of United States, ${ }^{2}$ but also worldwide.3,4 A TBL session is conducted in the form of a sequence of activities namely individual readiness assurance test (i-RAT), team-readiness assurance test (t-RAT), instructor clarification/mini-lecture and teamapplication exercise (t-App).

Most of the studies that investigated the benefits of TBL showed that its effects on student ability to apply knowledge are largely positive and are attributable to its process. ${ }^{5}$ However, its effect on student scores or academic performance has been equivocal. Neider et al.

Correspondence to: Dr. Memoona Mansoor, Department of

Medical Education, Islamabad Medical and Dental College,

Islamabad, Pakistan

E-mail:docmemoona@yahoo.com

Received: September 08, 2018; Revised: January 04, 2019;

Accepted: April 08, 2019 employed TBL in gross anatomy and embryology courses and concluded that the class average did not improve with the introduction of TBL. ${ }^{6}$ Koles et al. observed that TBL had a positive effect most pronounced in the students in lowest academic quartile.2,7 Wiener et al. observed that high performers benefitted more from the TBL on the other hand. ${ }^{8}$ Evidence suggests that TBL provides a platform for metacognitive instruction and allows students to benefit from the learning styles of others, thereby inculcating the ability to judge and improve their own learning. ${ }^{9}$

Medical literature from Pakistan using TBL as a teaching strategy is largely in its favour, with results showing that student satisfaction increases when traditional lecture is replaced by TBL. Hashmi conducted a modified form of TBL and compared it with the traditional lecture to discover its benefits on academic outcomes and students perceptions.10 Badar et al. sought students' opinion about TBL in comparison to lectures at Punjab Medical College, Faisalabad. ${ }^{11}$ Hameed et al. measured the impact of TBL on students' scores in comparison with didactic lectures. ${ }^{12}$ In this context, a study comparing TBL with other small group learning strategies seemed pertinent.

Shifa College of Medicine (SCM) has been following a learner-centred curriculum since 2008 with the main 
strategies of instruction include small group discussion (SGD) and problem-based learning (PBL). This study was conducted to determine if TBL had a greater impact on student performance compared to SGD as indicated by their end-of-module written examination scores.

\section{METHODOLOGY}

The study commenced after approval from the Institutional Review Board (IRB). It was a quasi-experimental, crossover study design. All the students of second year MBBS at Shifa College of Medicine academic year 2014-2015, were included except the repeaters. The students were first ranked into three categories (above average, average, and below average) on a quartile basis according to their percentage scores in the previous modular examination; and then based on non-probability sampling, were grouped into $A$ and $B$ ensuring equal representation of the three categories (Figure 1). TBL was used as an instructional strategy instead of SGD for teaching second year medical students over a five-week GIT (gastrointestinal tract) module. The module was designed along eight themes. The students' performance during the TBL sessions was scored. Each theme revolved around a relevant and contextual real-life case scenario that acted as a trigger. List of themes and the teaching strategy used is given in Table I. The curricular

Table I: Summary of the themes, number of sessions and subcategories of students.

\begin{tabular}{|c|c|c|c|}
\hline & $\begin{array}{l}\text { Categories of } \\
\text { students }\end{array}$ & Group A & Group B \\
\hline $\begin{array}{l}\text { Themes learnt } \\
\text { with TBL }\end{array}$ & & $\begin{array}{l}1 \text { - } 4 \\
\text { Patient with } \\
\text { difficulty in } \\
\text { swallowing } \\
\text { Patient with } \\
\text { anterior abdominal } \\
\text { wall swelling } \\
\text { Patient with acute } \\
\text { abdomen } \\
\text { Patient with acute } \\
\text { epigastric pain }\end{array}$ & $\begin{array}{l}5 \text { - } 8 \\
\text { Patient with jaundice } \\
\text { Patient with chronic } \\
\text { diarrhea } \\
\text { Patient with acute } \\
\text { diarrhea } \\
\text { Patient with bleeding } \\
\text { per rectum. }\end{array}$ \\
\hline $\begin{array}{l}\text { No. of TBL } \\
\text { sessions }\end{array}$ & & 8 & 8 \\
\hline $\begin{array}{l}\text { Previous } \\
\text { results }\end{array}$ & $\begin{array}{l}\text { Above average } \\
\text { Average } \\
\text { Below average }\end{array}$ & $\begin{array}{r}13 \\
19 \\
9\end{array}$ & $\begin{array}{r}13 \\
19 \\
9\end{array}$ \\
\hline Gender & $\begin{array}{l}\text { Male } \\
\text { Female }\end{array}$ & $\begin{array}{l}15 \\
26\end{array}$ & $\begin{array}{l}18 \\
23\end{array}$ \\
\hline
\end{tabular}

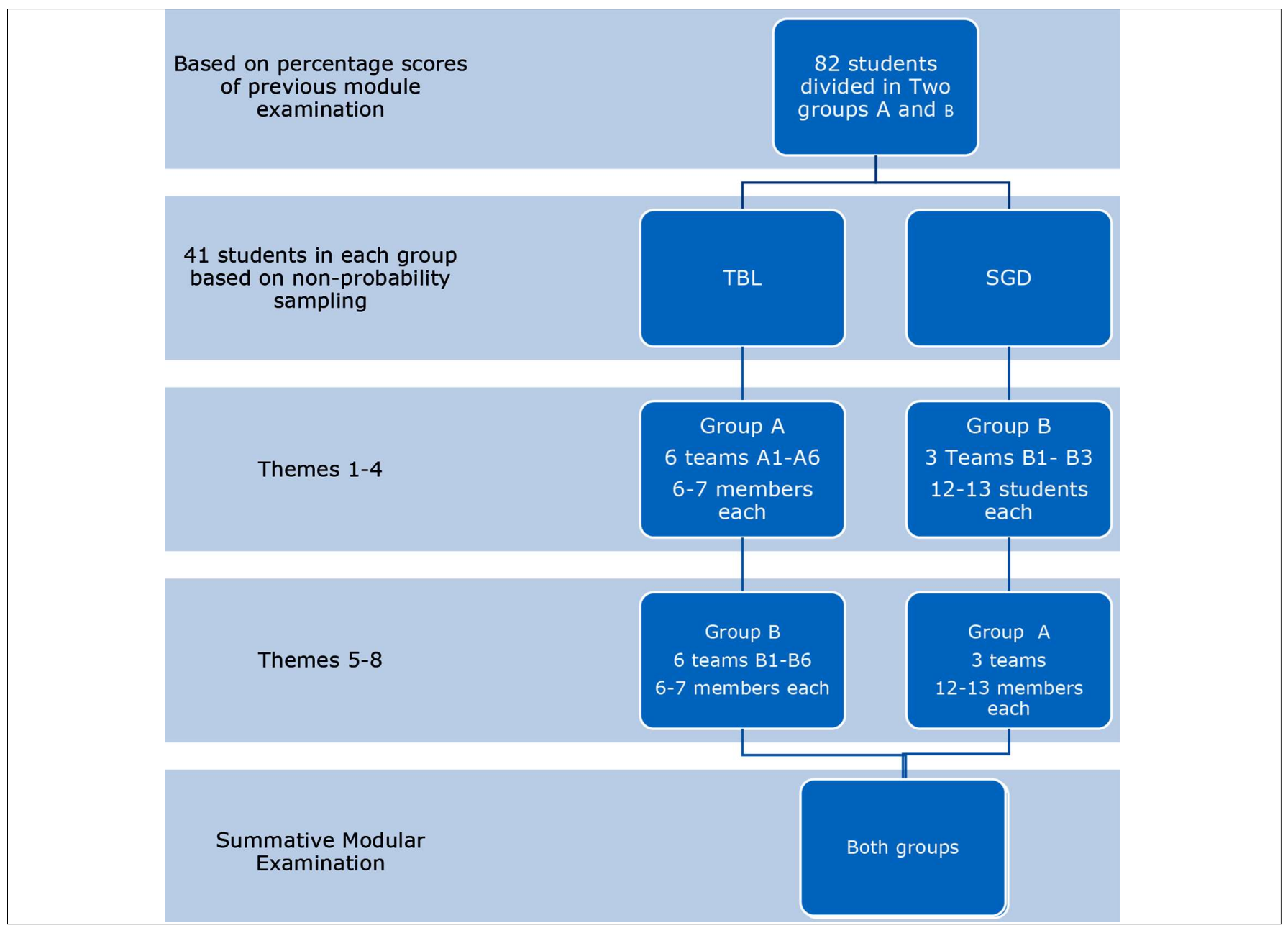

Figure 1: Division of students. 
content was delivered through small group discussions (SGD), large group sessions, team-based learning and skill lab sessions. The areas addressed included gross and micro-scopic anatomy, developmental and clinical anatomy, along with basic and applied physiology. The assessment of the module was done through type-A items and SAQs. For team-based learning scores of only type-A items were taken into account so that content validity and objectivity were not violated.

The TBL team members consisted of the principal investigator ( $\mathrm{PI}$ ), module director (an Assistant Professor in Anatomy) and an FCPS Trainee in Physiology. To

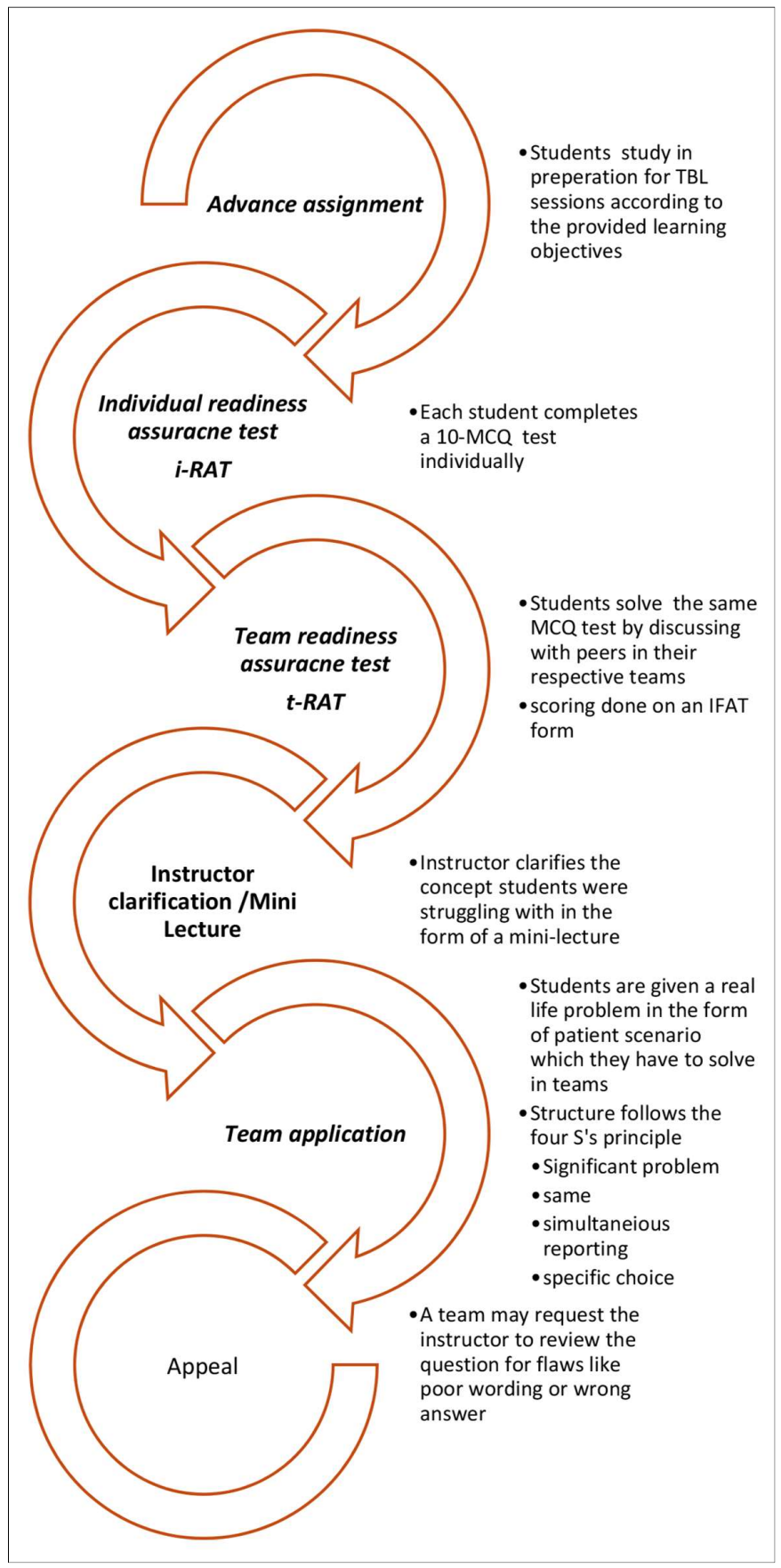

Figure 2: Process of team-based learning. sensitise the identified TBL faculty, a pilot TBL session was conducted in the immediately preceding module.

The students were oriented with TBL process by an introductory session, which was conducted by the PI. A power point presentation was given to the class on the first day of the GIT module and an informed consent was obtained about the use of the scores. The students were informed of the marking scheme of TBL sessions. A handout explaining the design, format, advantages and the marking scheme of TBL was also distributed among the students in this session (This handout had been uploaded to the modular Dropbox earlier). TBL sessions were run exactly in the format recommended by AMEE guide No. 65 (1) given in Figure 2.

Every TBL session was scored by assigning marks to each component activity and these scores were then counted towards internal assessment.

Learning objectives and time duration for both the SGD and TBL sessions were the same. The learning objectives were shared with the students via Dropbox link for that particular module as well as in the form of hard copies.

The SGD sessions were run in a discussion format with the faculty acting as facilitators. Students discussed the content by exchanging the information that helped them achieve their assigned objectives. Students could refer to the clinical scenario related to that particular theme, provided in the study guide, during their discussion. The facilitator was supposed to intervene only whereever necessary; involve reticent learners, provide guidance and clarify concepts as and when required. Every SGD was evaluated by the facilitators on the "learner's log" through a global rating scale.

The end-of-module written examination consisted of an MCQ paper designed by the subject experts. It was reviewed and revised on advice of department of health professions education (DHPE) for technical item flaws prior to printing. Questions were arranged in the sequence of themes and were in line with the assessment blue print. Total number of MCQs was 70 and the majority $(60 \%)$ was type A. Percent scores of end-of-module final summative $M C Q$ examination were obtained and statistical analysis was carried out through SPSS version 23. Independent sample t-test was applied to compare the overall scores of the two groups and the mean scores of the three categories of students (above average, average, and below average) of both groups ( $A$ and $B$ ). This was according to the respective themes they had covered with TBL. A p-value of $\leq 0.05$ was considered statistically significant.

\section{RESULTS}

The Cronbach alpha (reliability) of the end-of-module question paper was 0.7 . In the first half of the GIT module 
Table II: Comparison of the mean percentage scores of the students of both groups (TBL and SGD).

\begin{tabular}{l|c|c|c}
\hline Themes & Parameter & Mean & p-value \\
\hline $1-4$ & (TBL) Group A & $61.90 \pm 13.01$ & 0.41 \\
& (SGD) Group B & $59.65 \pm 11.56$ & \\
\hline $5-8$ & (SGD) Group A & $59.92 \pm 10.65$ & $0.030^{*}$ \\
& (TBL) Group B & $65.36 \pm 11.62$ & \\
\hline
\end{tabular}

*Statistically significant.

(Themes 1-4) overall comparison of mean percent scores show that the TBL group performed better than the SGD group, but the difference is insignificant $p=0.41$ (Table II). Comparison of mean scores of the three strata of students - above average, average, and below average - showed there is a slight difference in mean scores of the two groups, which is although not statistically significant but the scores are higher for the students studying with TBL than the ones studying with SGD.

In the second half of the module, Group B learned the last four themes (Themes 5-8) through TBL and Group A through SGD. The comparison of end-of-module exam scores of the last four themes showed TBL students performing significantly better than SGD students, $\mathrm{p}=0.30$ (Table II).

Comparison of the three categories of students - above average, average, and below average - showed the same trend as seen in 1-4 themes where there is a statistically insignificant difference in the mean scores with TBL students performing slightly better than SGD students.

\section{DISCUSSION}

Team-based learning was introduced in our setup to observe its impact on student scores. The present data showed inconclusive results, TBL-group students did perform better but the difference in scores was insignificant in the first half of the module and significant in second half.

A uniform distribution of the content throughout the module was aimed; both the groups were provided with same learning objectives regardless of the learning strategy along with the number, duration and timings of sessions. Despite the efforts for maintaining standardisation and uniformity, the first four themes might have been challenging for students as they contain more content of anatomy including oral cavity, anterior abdominal wall and peritoneum. These areas are difficult to handle for students when encountered for the first time. Therefore, there is a chance that both groups had to struggle; and TBL-group students although had better mean scores, did not show significant difference in their results.

The content of the last four themes (Themes 5-8) was relatively easy and included more of Applied Physiology. This might have helped TBL-group students obtain more marks leading to significant difference in scores. These observations were in line with the views of the subject experts responsible for designing and delivery of the module.

Differences in course structure and content and/or course difficulty have been speculated as reasons of insignificant differences in scores in various studies comparing TBL with small group learning techniques. 6,7

Another factor might be responsible for these finding is the skill of faculty members. It was not possible to assure same performance by all the faculty members facilitating the small group discussions because they varied in terms of teaching experience, age and gender. Differences in the style and skills of facilitators can result in variability in the quality of sessions in SGD. ${ }^{7}$

TBL-group students had to go the extra mile for their home assignment because the team application exercises were tough and consisted of clinical correlation of real life scenarios with basic science knowledge. In SGDs, clinical application is addressed occasionally. These factors might have resulted in higher but insignificant scores of group A during first half of module (Themes 1-4). Interestingly the results of last four themes (5-8) depicted a significant difference in examination scores with TBL students performing better than the SGD students.

Although small group learning did provide an opportunity of active learning, there was relatively less element of critical thinking and problem-solving. Mostly, it depended mainly on the skill of facilitators as to how much clinical relevance they could bring in the discussion by generating a debate.

On the other hand, TBL challenges students' knowledge through carefully structured activities and candid feedback which increases depth of their learning. ${ }^{7}$ Two important aspects of peer teaching and accountability inherent to TBL design are reasons of its positive effects. ${ }^{13}$

Peer evaluation was done at the end of each half of the module and accounted for $5 \%$ of the TBL score; and students were aware of this fact. However, readiness assurance tests (i-RAT and t-RAT) and team application (t-App) exercises created a sense of commitment in students and increased their motivation to study better. ${ }^{14}$ Repeated testing in the form of readiness assurance tests (i-RAT and t-RAT) can also be attributed for better learning. ${ }^{5}$ Carefully crafted application exercises generated constructive debates leading to competitive environment among teams. ${ }^{15}$ TBL faculty put real time efforts to make the sessions palatable and engaging for students. Making MCQs for RAT and t-Application exercises, preparing mini-lectures and organising the session were tough jobs. SGD lacked all these features, there were no clinical problems presented; it was the discretion of facilitator to relate to clinical case mentioned in study guide. Students usually confine themselves to content mentioned in the learning 
objectives during their discussion. They were assessed only on their individual performance. Many students did not come prepared nor did they bother about their grades. Some students had to do most of the work in the group. Therefore, there were remote chances of experiencing clinical debate and correlating the clinical problems with basic sciences knowledge. There seems little possibility that end-of-module written assessment is the reason for the above mentioned findings.

The results of this study cannot be generalised due to a number of limitations. It shows the effect of TBL in a single course/module with a limited sample size and these results were not compared with any other medical college. Another limitation is the absence of control group which could not be created because student could not be deprived of a unique educational experience.

\section{CONCLUSION}

TBL is equally effective as an instructional method as SGD. When TBL was implemented in a basic science course, it could not result in significant improvement in learning neither did it lead to any reduction or deterioration of scores.

\section{ETHICAL APPROVAL:}

The study commenced after approval from the Institutional Review Board (IRB).

\section{CONFLICT OF INTEREST:}

Authors declared no conflict of interest.

\section{AUTHORS' CONTRIBUTION:}

MM: Conducted the research, analyzed and interpreted the data; primary writer of the manuscript.

SMA: Contributed to the conception and design of work. AJ: Managed the research project providing necessary logistic and academic support throughout; reviewed and revised the manuscript and contributed important intellectual content.

\section{REFERENCES}

1. Parmelee D, Michaelsen LK, Cook S, Hudes PD. Team-based learning: A practical guide: AMEE guide No. 65. Med Teach 2012; 34:e275-87.
2. Koles PG, Stolfi A, Borges NJ, Nelson S, Parmelee DX. The impact of team-based learning on medical students' academic performance. Acad Med 2010; 85:1739-45.

3. Haidet P, Kubitz K, McCormack WT. Analysis of team-based learning literature: TBL comes of age. J Excell Coll Teach 2014; 25:303-33.

4. Fatimi M, Hartling L, Hillier T, Campbell S, Oswald AE. The effectiveness of team-based learning on learning outcomes in health professions education: BEME guide no. 30. Med Teach 2013; 35:e1608-24.

5. Thomas PA, Bowen CW. A controlled trial of team-based learning in an ambulatory medicine clerkship for medical students. Teach Learn Med 2011; 23:31-6.

6. Nieder GL, Parmelee DX, Stolfi AS, Hudes PD. Team-based learning in a medical gross anatom and embryology course. Clin Anat 2005; 18:56-63.

7. Koles P, Nelson S, Stolfi A, Parmelee D, Destephen D. Active leaning in year 2 pathology curriculum. Med Educ 2005; 39:1045-55.

8. Weiner $\mathrm{H}$, Plass $\mathrm{H}$, Marz R. Team-based learning in intensive course format for first-year medical students. Croat Med $\mathrm{J}$ 2009; 50:69-76.

9. Mcinerney MJ, Fink LD. Team-based learning enhances long term memory retention and critical thinking in an undergraduate Microbial Physiology Course. Microbiol Educ 2003;4:3-12.

10. Hashmi NR. Team-based learning (TBL) in undergraduate medical education. J Coll Physicians Surg Pak 2014; 24:553-6.

11. Badar S, Hasnain Mu, Hashmi YZ. Searching the way to keep students awake in classroom. Biomedica 2014; 30:62-9.

12. Hameed S, Khalid T, Aslam S, Ahmed M, Farhan F, Batool Z, et al. Team-based learning in pathology: Effect on test scores and student satisfaction. Pak Armed Forces Med J 2017; 67:3.

13. Letassy NA, Fugate SE, Medina MS, Stroup JS, Britton ML. Using team-based learning in an endocrinology module taught across two campuses. Am J Pharm Educ 2008; 72:103.

14. Zingone MM, Franks AS, Guirguis AB, George CM, Thompson AH, Heidel RE. Comparing team-based and mixed active-learning methods in an ambulatory care elective course. Am J Pharm Educ 2010; 74:160.

15. Isbell JA, Makeeva V, Caruthers K, Brooks WS. The impact of team-based learning on physician assistant students' academic performance in gross anatomy. J Physician Assist Educ 2016; 27:126-30. 